\title{
Effects of knot area ratio on the bending properties of cross-laminated timber made from Korean pine
}

\author{
Sung-Jun Pang ${ }^{1} \cdot \mathrm{Kug}^{-B o} \mathrm{Shim}^{2} \cdot$ Keon-Ho Kim ${ }^{2}$ (D)
}

Received: 2 April 2020 / Accepted: 14 December 2020 / Published online: 15 January 2021

(C) The Author(s) 2021

\begin{abstract}
The effect of knot clusters on the bending properties of Korean pine (Pinus koraiensis) cross-laminated timber (CLT) was analyzed to increase the utilization of lowquality lumber. The laminae used to manufacture the CLT were classified into five groups, four major layer groups, and one minor layer group, by mechanical grade and knot area ratio (KAR) of the lamina. Out-of-plane bending tests were conducted on CLT made from each layer group. The modulus of elasticity (MOE) of the manufactured CLT was closely correlated with the MOE of each individual major axis lamina. In the case of the modulus of rupture (MOR) of the CLT, the KAR of the laminae used in the major axis layer was more significantly affected than the MOE. The main finding is that the lower fifth percentile MOR value of the CLT specimens with large knots (KAR > 0.5) was higher than the acceptable reference value of E3 grade CLT (ANSI/APA PRG 320) made from a similar lamina grade. Therefore, the use of low-quality lumber to manufacture CLT can be expanded under the condition of limitation of the greater KAR.
\end{abstract}

Part of this article was presented in proceeding of spring annual conference of the Architectural Institute of Korea (Vol.37 No.1), April 27-28, 2017, Jeju, Korea.

Keon-Ho Kim

keon@korea.kr

Sung-Jun Pang

pangsungjun@snu.ac.kr

Kug-Bo Shim

kbshim@korea.kr

1 Department of Agriculture, Forestry and Bioresources, Seoul National University, Gwanak-ro 1, Gwanak-gu, Seoul, Republic of Korea

2 Department of Forest Products, National Institute of Forest Science, 57 Hoegiro,

Dongdaemun-gu, Seoul 02455, Republic of Korea 


\section{Introduction}

Demand for timber construction materials has increased globally in recent years, not only due to aesthetic preferences and structural advantages, but also because the use of timber reduces carbon emissions. The SOM (2013) reported that hybrid construction systems using both concrete and timber reduce $\mathrm{CO}_{2}$ emissions by $60-75 \%$.

The structural safety of timber buildings is closely related to the performance of the structural engineered wood, such as glued laminated timber or cross-laminated timber (CLT). Every individual piece of structural engineered wood is graded by its visual or mechanical characteristics before being used in construction projects. The grades of structural timber specified in the Korean building code refer to the standards and specification of wood products, as published by the National Institute of Forest Science and the Korean Standards (KS F 3020: 2013 and KS F 3021: 2018). In the KS F 3021, the upper limit for the knot area ratio (KAR) in machine stress rated (MSR) lamina was determined to be $17 \%$ for the most outer layer, $25 \%$ for the outer layer, and 33\% for the inner layer. These are the criteria for layer material in glued laminated timber (GLT), and the criteria for layer material in CLT have not yet been established.

Representative softwood species in Korean forests include red pine, Japanese larch, Pinus rigida, and Korean pine. Korean pine forests spread across an area of 23,308,094 ha in 2016 by statistical annual report for forest industry (Korea Forest Service 2018). Korean pine lumber is primarily used for non-structural purposes, such as appearance grade lumber and furniture, because cutting, drying, planing, and other treatments are relatively easy to perform (Chong and Park 2008). However, knot cluster (Fig. 1) due to the growth characteristics of Korean pine presents a major disadvantage in its utilization as a structural element in engineered wood (Song et al. 2015). Yeh (1996) reported that knots were one of the main factors that reduce the strength of engineered wood products. Oh et al. (2000) found many researchers that had studied variations in mechanical properties based on knots of various species to use timber resources more economically.

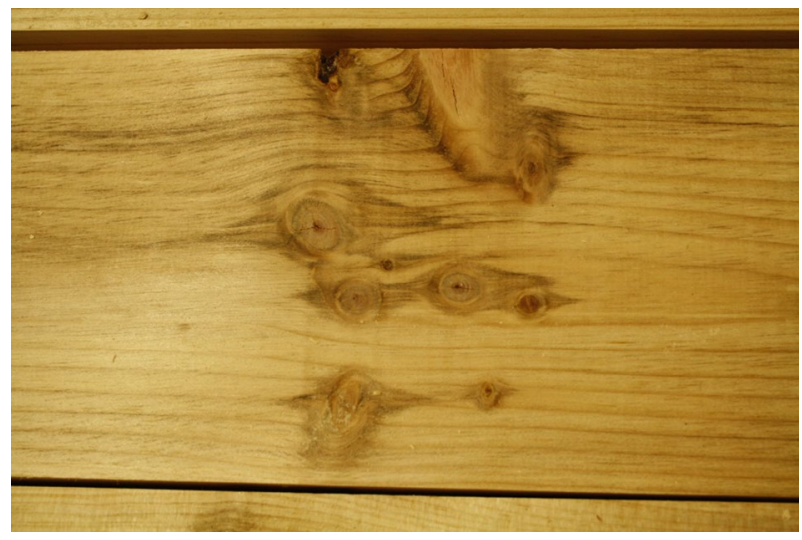

Fig. 1 Example of knot cluster in a Korean pine lamina 
CLT is an emerging engineered wood product made by gluing graded laminae together to manufacture structural panels. The axes of CLT are classified as the major and minor axis. The published quality standards of CLT, found in ANSI/APA PRG 320 (2018), explain that the lamina of the minor axis layer must meet visual grade requirements because the quality of that particular layer affects the bonding properties of CLT. Bending strength is an important design parameter required for structural CLT used in building construction. CLT walls need to meet out-of-plane bending performance requirements against wind and seismic load. Pang and Jeong (2019) reported that the load-carrying capacity of larch CLT increased with the span-to-depth ratio of the specimen in the out-of-plane bending test. In contrast, the load-carrying capacity of Korean pine CLTs did not increase as the span-to-depth ratio increased, and the failure occurred around knots. In an experimental test by Hematabadi et al. (2020), the modulus of rupture (MOR) of CLT made from poplar (Populus alba) increased only $1 \%$ (from 41.12 to $42.7 \mathrm{MPa}$ ) by increasing span-todepth ratio from 15 to 25 . In a numerical study by Flores et al. (2016), the load-carrying capacity of the CLT decreased by $50 \%$ as the span-to-depth ratio increased 2.5 times (from 3.3 to 8.3), since the failure mode (crack formation) was changed due to an increase in the span-depth ratio.

A knot cluster in the Korean pine may cause this reduction in CLT bending capacity. Therefore, to improve the structural performance of Korean pine CLTs, a better understanding of the effects of knot cluster on CLT strength is required. To achieve this understanding, the bending performance of CLT made from Korean pine was investigated as a function of the KAR.

\section{Materials and methods}

\section{Specimens}

Korean pine (Pinus koraiensis), cut from the Gapyeong area of the Gyeonggi Province, was used to build the CLT specimens. The trees were over 30 years old. The size of laminae for CLT manufacturing was $30 \mathrm{~mm}$ thick, $100 \mathrm{~mm}$ wide, and $3600 \mathrm{~mm}$ long. As measured by Korean Standards, the specimens' air- and oven-dry densities were $0.35( \pm 0.07) \mathrm{g} / \mathrm{cm}^{3}$ and $0.40( \pm 0.04) \mathrm{g} / \mathrm{cm}^{3}$, with a moisture content of $4.78( \pm 1.47) \%$. The laminae were sorted by the mechanical stress rated machine according to the lamina grade in KS F 3021. A length segment of $2700 \mathrm{~mm}$, which corresponds to the span of the CLT, in a total lamina length of $3600 \mathrm{~mm}$ was graded and no finger joints were used. The modulus of elasticity (MOE) distribution of 1400 boards by MSR for laminae is shown in Fig. 2. Approximately, 55\% of the total laminae were categorized in E8 and E9 grades. The grade means that the modulus of elasticity (MOE) is not lower than the number (GPa) after the character " $E$." The E8 grade means the MOE range is greater than or equal to $8 \mathrm{GPa}$ and less than $9 \mathrm{GPa}$. The MOE range for the $\mathrm{E} 9$ grade is above $9 \mathrm{GPa}$ and less than $10 \mathrm{GPa}$. These E8 and E9 grade laminae were used for the major axis, while the E7 and lower grade laminae were used for the minor axis of the CLT panel. 


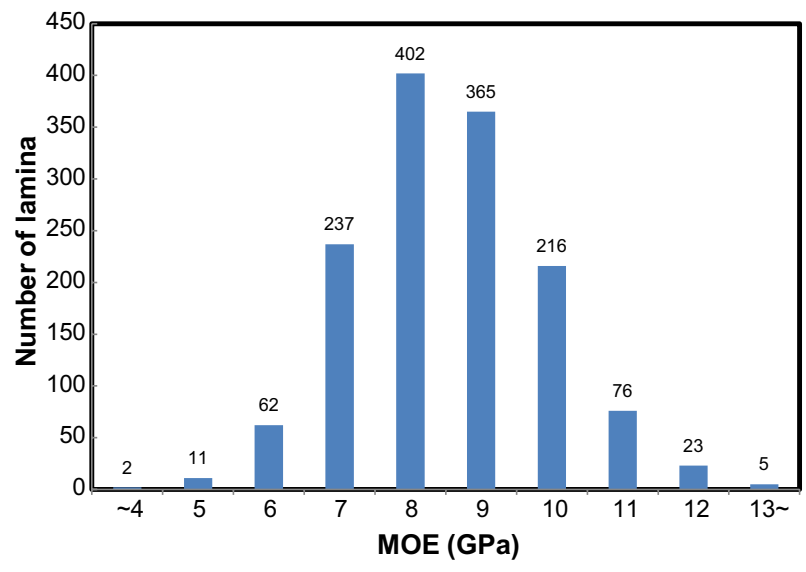

Fig. 2 MOE distribution of Korean pine laminae by MSR

The graded structural lumber was used as laminae to form the CLT, according to CLT handbook (Karacabeyli and Douglas 2013). The grading rules of the National Lumber Grading Authority (NLGA 2013) were used to evaluate the maximum KAR (Lam et al. 2005). The KAR is well known to show a good correlation with the strength of lumber (Roblot et al. 2010). The KAR is defined as the ratio of the knot area projected on the cross section versus the total cross-sectional area. Figure 3 shows the concept of KAR and knot size measurement. If the distance between some knots is less than $150 \mathrm{~mm}$ in the longitudinal direction, it was calculated as one KAR. In this study, the KAR was calculated by Eq. 1, and detailed information for calculating KAR can be found in ASTM D3737 (2018):

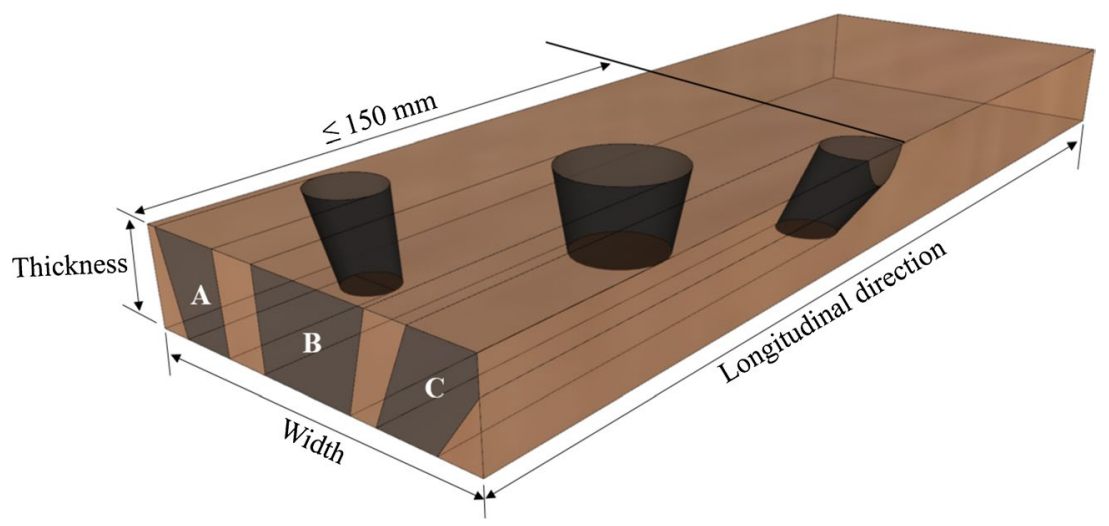

Fig. 3 Knot areas (A, B, and C) projected on the cross-sectional area (thickness $\times$ width) to calculate the KAR 
Table 1 KAR distribution of laminae

\begin{tabular}{lllllllll}
\hline KAR $^{\mathrm{a}}$ & 0 & $0 \sim 0.1$ & $0.1 \sim 0.2$ & $0.2 \sim 0.3$ & $0.3 \sim 0.4$ & $0.4 \sim 0.5$ & $0.5 \sim$ & Total \\
\hline No. of laminae $^{\mathrm{b}}$ & 1 & 1 & 24 & 80 & 172 & 189 & 933 & 1400 \\
${\text { Ratio }(\%)^{\mathrm{c}}}^{0.1}$ & 0.1 & 1.7 & 5.7 & 12.3 & 13.5 & 66.6 & 100 \\
\hline
\end{tabular}

${ }^{\mathrm{a}}$ Knot area ratio, ${ }^{\mathrm{b}}$ number of laminae, ${ }^{\mathrm{c}}$ number of laminae/total number of laminae $\times 100$

Table 2 Layer composition of CLT specimens

\begin{tabular}{|c|c|c|c|c|}
\hline Classification & E8A & E8B & E9A & E9B \\
\hline Number of CLT samples & 20 & 30 & 19 & 31 \\
\hline \multicolumn{5}{|l|}{ Major axis } \\
\hline MSR grade ${ }^{a}$ & E8 & & E9 & \\
\hline $\mathrm{KAR}^{\mathrm{b}}$ & $\leq 0.5$ & $>0.5$ & $\leq 0.5$ & $>0.5$ \\
\hline No. of laminae ${ }^{c}$ & $125(8.9 \%)^{\mathrm{d}}$ & $289(20.6 \%)$ & $130(9.3 \%)$ & $235(16.8 \%)$ \\
\hline \multicolumn{5}{|l|}{ Minor axis } \\
\hline KAR & $\leq \mathrm{E} 7$ & & & \\
\hline No. of laminae & $312(22.3 \%)$ & & & \\
\hline
\end{tabular}

${ }^{\mathrm{a}} M S R$ Machine stress rate, ${ }^{\mathrm{b}} K A R$ knot area ratio, ${ }^{\mathrm{c}}$ number of laminae, ${ }^{\mathrm{d}}$ number of laminae/total number of laminae $\times 100$

$$
\mathrm{KAR}=\frac{\text { Knot area projected onto cross section }}{\text { Cross-sectional area }}
$$

The distribution of KAR of the laminae is shown in Table 1. The number of laminae with more than KAR 0.5 was 933 samples, and it was $66.6 \%$ of the total laminae. For E-rated structural laminations based on the NLGA grading rules, the KAR should not occupy more than 0.5 of the cross-sectional area (NLGA 2013). Thus, in this study, the laminae were classified into Group A (KAR $\leq 0.5$ ) or Group B (KAR $>0.5)$ by KAR.

The layer composition of the CLT specimens is shown in Table 2. Four types of CLT specimen (E8A, E8B, E9A, and E9B) were manufactured depending on the MSR grade and KAR of the lamina. The first two characters indicate the MSR grade, while the third character indicates the KAR of the outer lamina, where an A means that the KAR is 0.5 or less, and a B means the KAR exceeds 0.5 . The ratio of major axis laminae for B groups $(20.6 \%$ for E8B, $16.8 \%$ for E9B) was higher than that for A groups (8.9\% for E8A, 9.3\% for E9A). The target number of CLT specimens was at least 30, and laminae that were excessively curved or twisted were not used to make CLT. Due to the small number of major axis laminae for A group, the number of CLT specimens for the E8A and E9A group was 20 and 19, respectively.

The size of the CLT specimens was $90 \mathrm{~mm}$ (thickness) $\times 300 \mathrm{~mm}$ (width) $\times 2900 \mathrm{~mm}$ (length). The CLT specimens contain three layers in total: two major and one minor axis. The two major axis layers consist of three laminae per layer, running parallel to the longitudinal direction of the CLT panel. The minor axis layer was fabricated from 29 
laminae, placed perpendicular to the longitudinal direction. A phenol-resorcinol resin (D-40, Oshika Corporation, Japan) adhesive was used to face bond (layer to layer) each layer in the CLT. The amount of adhesive used was $250 \mathrm{~g} / \mathrm{m}^{2}$ on both faces, and the pressure and the press time were $0.8 \mathrm{MPa}$ and $24 \mathrm{~h}$ at room temperature, respectively.

\section{Bending performance test}

The out-of-plane bending performance of the CLT panel was tested by EN 16351 (2014) as shown in Fig. 4. The four-point bending test was conducted by a 30-ton MTS test system (CN/E45:305). The span distance and crosshead speed were $2700 \mathrm{~mm}$ and $10 \mathrm{~mm} / \mathrm{min}$, respectively. The modulus of rupture (MOR) and MOE of the CLT were calculated by Eqs. (2) and (3), respectively, according to ASTM D198-09 (2009). The lower fifth percentile value of the MOR for each CLT group was determined by nonparametric lower fifth percentile point estimate according to ASTM D 2915-10 (2010). The test values were arranged in ascending order. Beginning with the lowest value, il $(n+1)$ was calculated. The lower fifth percentile value was interpolated by Eq. (4):

$$
\text { MOR }=\frac{1.2 P_{\max } L}{w t^{2}}
$$

MOR: Modulus of rupture (MPa), $P_{\max }$ : maximum load (N), L: span distance (mm), $w$ : width of CLT (mm), $t$ : thickness of CLT (mm).

$$
\mathrm{MOE}=\frac{a}{4 w t^{3}}\left(\frac{P}{\Delta}\right)\left(3 L^{2}-4 a^{2}\right)
$$

MOE: Modulus of elasticity (GPa), $P$ : load at proportional limit, $\Delta$ : deflection at proportional limit $(\mathrm{mm}), L$ : span distance $(\mathrm{mm}), a$ : distance between the support and the loading point (mm), w: width of CLT (mm), $t$ : thickness of CLT (mm).

Lower 5th percentile point estimate $=\left[\frac{5}{100}(n+1)-(j-1)\right]\left[x_{j}-x_{(j-1)}\right]+x_{(j-1)}$

$n$ : Total number of samples, $j$ : the lowest order of the test value when $i /(n+1) \geq 0.05, i$ : the order of the test value, $x_{i}$ : $i$ th value.

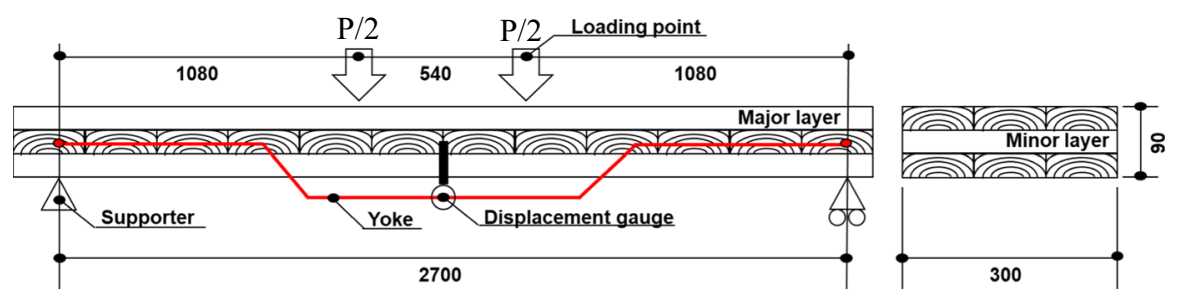

Fig. 4 Schematic diagram of the four-point bending test applied to the CLT specimens 


\section{Results and discussion}

\section{Failure mode}

The typical failure modes of CLT specimens are shown in Fig. 5. All specimens failed near the knots at the bottom of the major axis layer. Since Korean pine is known to contain a high number of knots, especially knot cluster, this phenomenon was expected. The tension failures occurred abruptly along the grain toward the adjacent minor axis layer. The failure initiated at knots near the bottom major axis layer and then transferred to the rolling shear of the minor axis layer. Blass and Görlacher (2000) also reported that splitting failure in the bottom layer created rolling shear failure across the annual ring due to the low rolling shear stiffness of timber. Ehrhart and Brandner (2018) further investigated the rolling shear properties of hardwood species, which were found to be greater than those of softwood. Therefore, mixed species CLTs composed of both softwood and hardwood (e.g., softwood major axis and hardwood minor axis layers) may improve the bending performance of CLT panels.

\section{Probability distributions of bending properties for CLT types}

Normal distribution curves of MOR and MOE for four types of CLT panels are shown in Fig. 6 to help visualize the effect of the KAR of the major axis on the bending performance of the panels. Figure 6 a shows that the MOR values of E8A and E9A were higher than those of E8B and E9B, respectively. The MOR

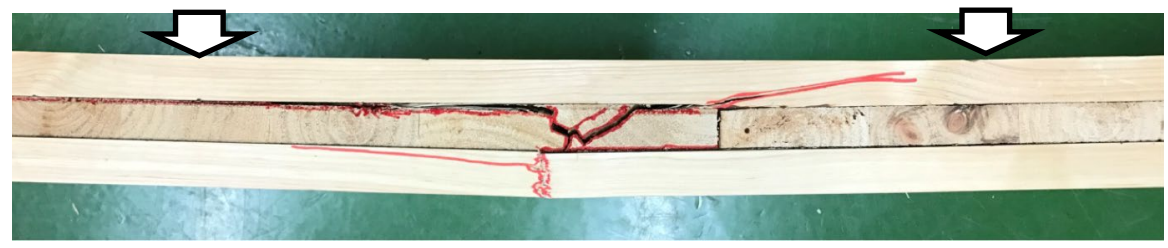

(a)

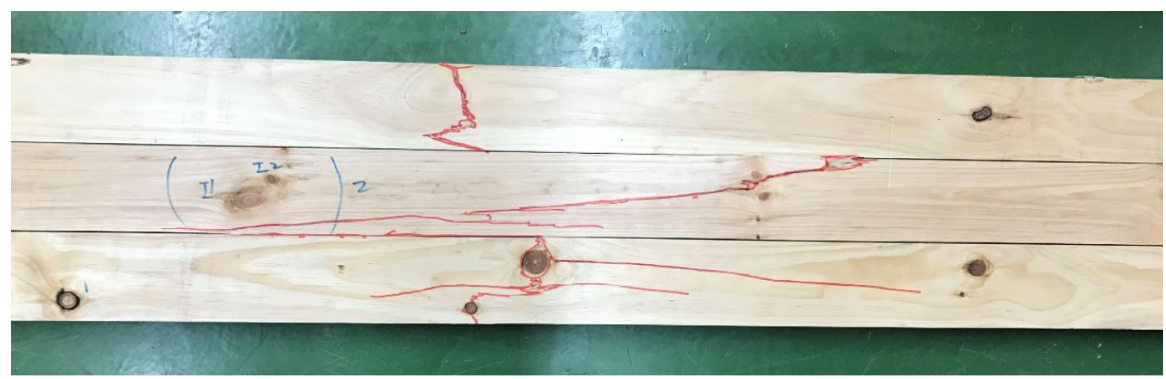

(b)

Fig. 5 Typical failure modes of CLT specimens by out-of-plane bending (a: side view, b: bottom view, arrow: the location of the loading heads) 


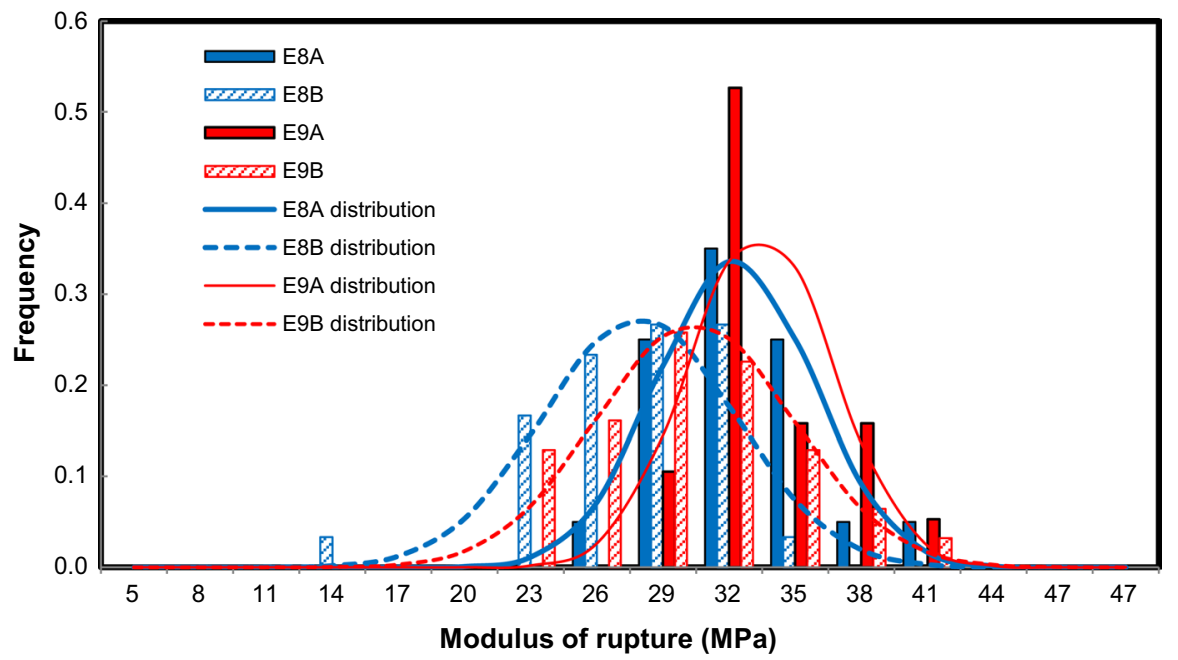

(a)

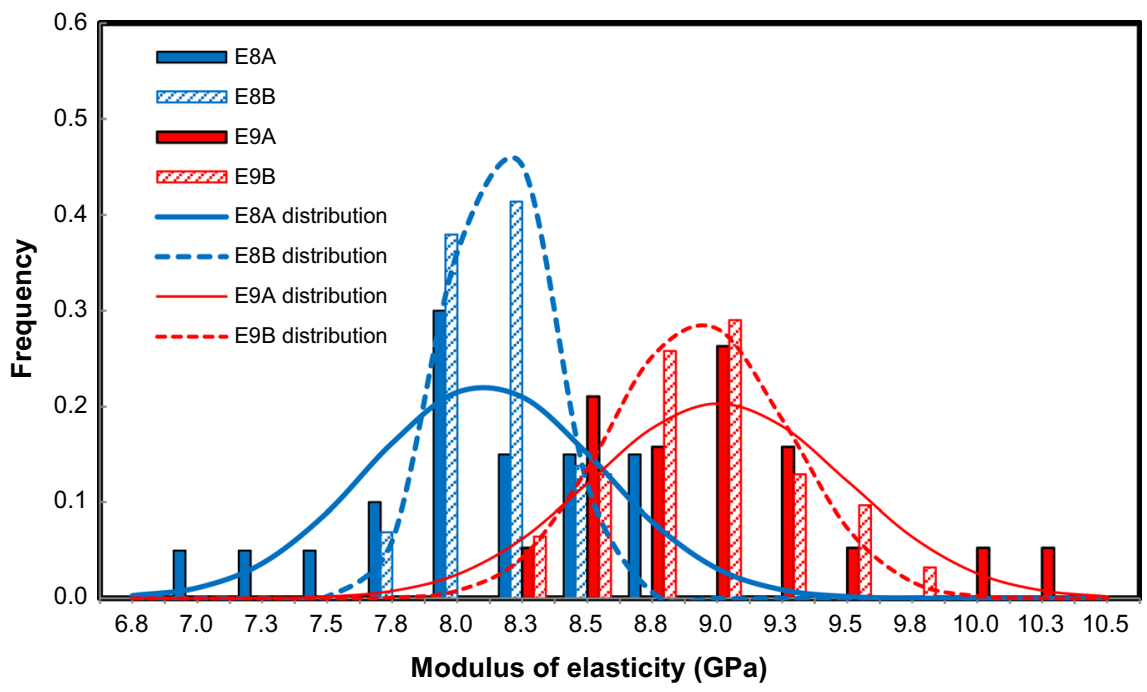

(b)

Fig. 6 Probability density distribution of MOR (a) and MOE (b) for each CLT panel type

distribution of the A group (samples with KAR values less than 0.5) was higher than the B group MOR distribution. Although the E8A CLTs were made by E8 grade laminae for the major layer, the MOR distribution of the E8A CLTs was a higher value than the E9B CLTs, which were manufactured with E9 grade laminae. These results indicate that the distribution of MOR is more significantly affected by the KAR than the MOE of the constituent laminae. It should be noted 
that the KAR was subdivided into two groups based on KAR 0.5, and the MOE was subdivided into E9 and E8 with a difference of $1 \mathrm{GPa}$.

In contrast, the MOE distribution values of the CLT panels were more strongly affected by changes to lamina MOE than KAR (Fig. 6b). Both of the MOE distributions of the E9 groups were higher values than the E8 groups. When the KAR exceeded 0.5 (B groups), the MOE distributions were more concentrated around the average value than the A groups. The MOE variation for layers with large knots may be smaller than for layers with or without small knots.

The cumulative distribution of MOR in the CLT specimens is shown in Fig. 7. The distributions of E8A (Fig. 7a) and E9A (Fig. 7b) were located more to the right side than the E8B and E9B panels. In particular in the A group, the lower tail of the MOR distributions shifted to higher values, compared to the upper tail. Thus, the lower fifth percentile values were significantly increased by limiting the KAR. In addition, the variation of the MOR also decreased, in a similar fashion to the MOE distributions, by limiting the KAR.

\section{Characteristic values for CLT types}

Results of statistical analysis [ $t$ test, significant difference $(\alpha)=0.05$ ] between the CLT types are shown in Table 3. Generally, when the $p$ value is less than 0.05 , the two types are considered statistically different (Vázquez et al. 2015; Sedighi Gilani et al. 2017). The $p$ value of the MOE between E8A and E8B was greater than 0.05. The $p$ value between E9A and E9B was also greater than 0.05. Thus, when the CLT specimens were made using similar MOE layers, the total MOE of the CLT was not significantly different, even though there were different KAR values in the laminae. However, the $p$ value between all CLT panels made from E8 (E8A + E8B) and those made from E9 (E9A+E9B) laminae were zero. This means that the CLT panels made of different MOE layers did result in significantly different total panel MOE values, regardless of KAR.

When comparing MOR values of different CLT panels, the $p$ values were less than 0.05 in all comparisons. According to the KAR limit (E8A and E8B, and E9A and E9B), the CLT panel's MOR distributions were significantly different. In addition, the MOR distribution of CLT panels was also significantly different when the MOE of the major layer was varied, without considering the KAR limit. Therefore, these results show that the MOR distribution of CLT was significantly affected by both the lamina MOE and KAR of the major axis layer.

The bending properties of the CLT specimens, sorted by the quality of the major axis layer, are shown in Fig. 8 and Table 4. The average MOR of CLT specimens composed of E8 and E9 major axis layers were 28.2 and 30.1 MPa, respectively. The average MOR of A type CLT, E8A and E9A, was $16.5 \%$ and $10.4 \%$ higher than the $\mathrm{B}$ type CLT, E8B, and E9B, respectively. Interestingly, the fifth percentile value of E8A (25.09 MPa) was 29.7\% higher than that of E8B (19.34 MPa). The fifth percentile value of E9A (26.82 MPa) was also $23.7 \%$ higher than that of E9B (21.69 MPa). The E9B CLTs were manufactured by E9 grade laminae for the major layer, but the fifth percentile MOR of the E9B CLTs was 14\% lower than that of E8A CLTs, which 


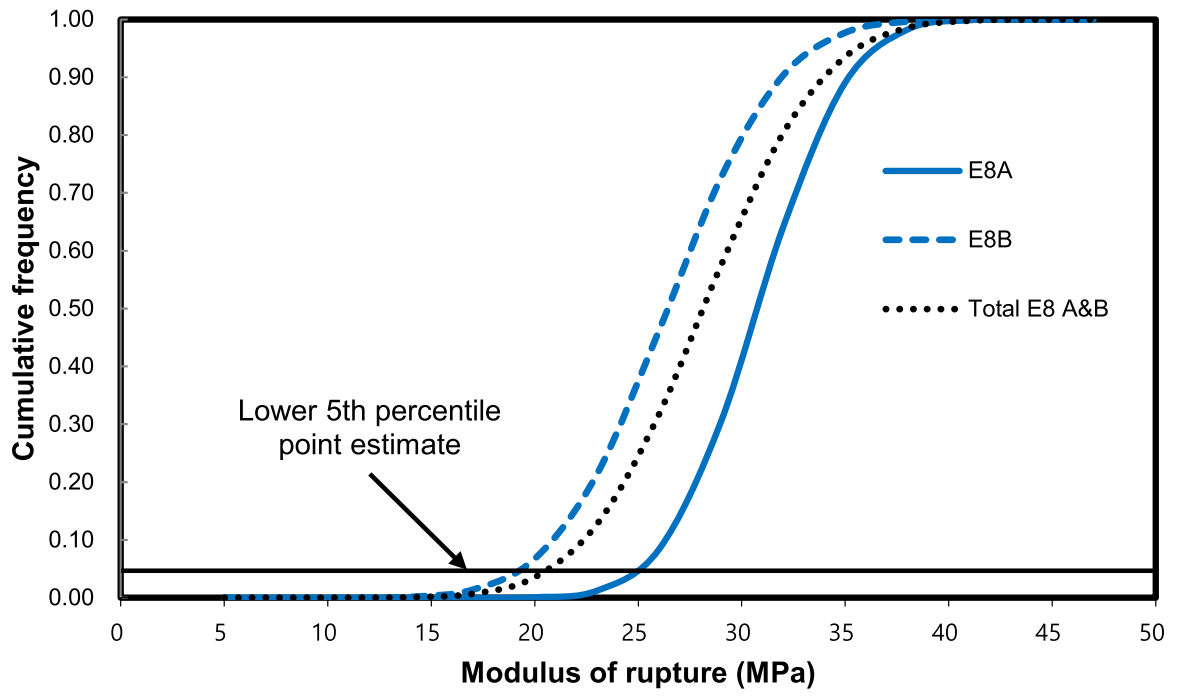

(a)

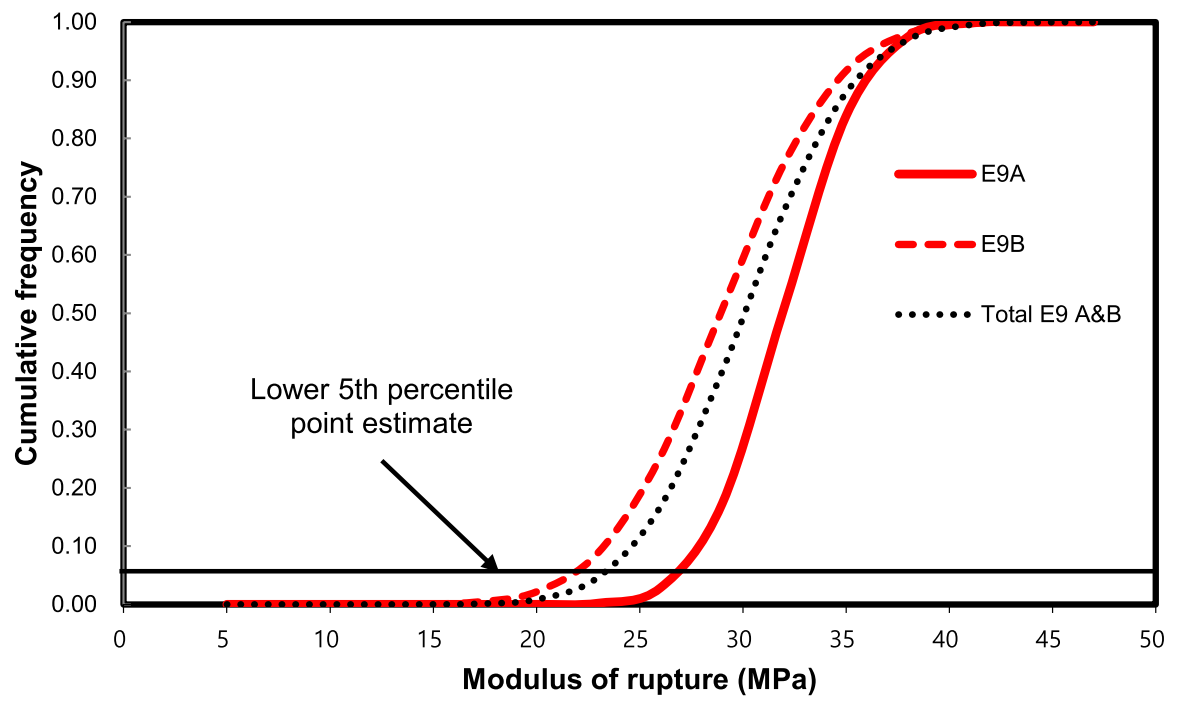

(b)

Fig. 7 Cumulative distribution for modulus of rupture values of CLT specimens depending on the KAR. Note that $\mathbf{a}$ and $\mathbf{b}$ are the MOR distributions of CLTs using E8 and E9 major layers, respectively

were manufactured with E8 grade laminae for major layer. Thus, these results show that the KAR of the major axis layer of the CLT significantly affected the bending strength of the CLT panel.

For MOE values, the E8 and E9 CLT specimens showed similar results with different KAR groups. The MOE of CLT specimens in E8A (7.98 GPa) was 0.7\% 
Table 3 Statistical analysis $(t$ test) between CLT panel types $(\alpha=0.05)$

\begin{tabular}{lll}
\hline Comparison & $p$ value & \\
\cline { 2 - 3 } & MOE & MOR \\
\hline E8A and E8B & 0.5599 & 0.0005 \\
E9A and E9B & 0.5174 & 0.0143 \\
E8 CLT (E8A+E8B) and E9 CLT & 0.0000 & 0.0316 \\
$\quad($ E9A + E9B) & & \\
\hline
\end{tabular}

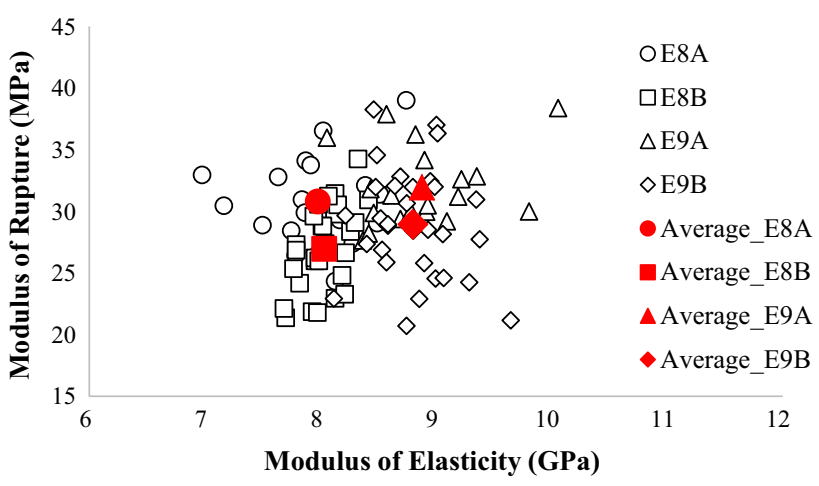

Fig. 8 Modulus of rupture (MOR) over modulus of elasticity (MOE) for CLT specimens

Table 4 MOE and MOR values of CLT by the quality of the major axis layer

\begin{tabular}{|c|c|c|c|c|}
\hline \multirow[t]{2}{*}{ CLT type } & \multirow{2}{*}{$\begin{array}{l}\text { Number of speci- } \\
\text { mens }\end{array}$} & \multicolumn{2}{|c|}{ Modulus of rupture (MPa) } & \multirow{2}{*}{$\begin{array}{l}\text { Modulus of } \\
\text { elasticity } \\
\text { (GPa) } \\
\text { Mean }\end{array}$} \\
\hline & & Mean & $\begin{array}{l}\text { Fifth percentile }(75 \% \\
\text { confidence) }\end{array}$ & \\
\hline E8A & 20 & $30.76(0.11)^{\mathrm{a}}$ & 25.09 & $7.98(0.06)$ \\
\hline E8B & 30 & $26.41(0.16)$ & 19.34 & $8.04(0.02)$ \\
\hline Total $^{\mathrm{b}}(\mathrm{E} 8)$ & 50 & $28.15(0.16)$ & 20.73 & $8.01(0.04)$ \\
\hline E9A & 19 & $31.93(0.10)$ & 26.82 & $8.88(0.05)$ \\
\hline E9B & 31 & $28.93(0.15)$ & 21.69 & $8.80(0.04)$ \\
\hline Total (E9) & 50 & $30.07(0.14)$ & 23.13 & $8.83(0.05)$ \\
\hline
\end{tabular}

aParentheses: coefficient of variation. "'Total” of both A and B

lower than that in E8B (8.04 GPa). The MOE of E9A (8.88 GPa) was $0.9 \%$ higher than E9B $(8.80 \mathrm{GPa})$. This is an expected result if the different KAR groups within the E8 or E9 grade do not affect the MOE of the CLT specimens. The effect of knot on MOE was not large compared to the effect on MOR. The average MOE of E8 CLTs $(8.01 \mathrm{GPa})$ was similar to the MOE grade of the major layers (E8). The average MOE value of the E9 CLTs $(8.83 \mathrm{GPa})$ was lower than the MOE of the major 
layers (E9), but the difference was not significant. These results show that the MOE of CLT was influenced by the MOE grade of the major axis layers. Therefore, the MOE grade and KAR of the major axis layer of a CLT panel can be used to predict the bending performance of a CLT panel.

The experimentally measured bending properties were compared with bending performance requirements for CLT grades in published standards. The CLT grades and bending properties for three-layer CLT in ANSI/APA PRG 320 (2018) are provided in Table 5. Since the standard structural properties of CLT provided by the ANSI are presented as a bending moment capacity $(\mathrm{N} \mathrm{mm})$ and a bending stiffness $\left(\mathrm{N} \mathrm{mm}{ }^{2}\right.$ ), to compare with the experimentally measured bending properties, the tabulated bending moment capacity was divided by the sample section modulus $\left(\mathrm{mm}^{3}\right)$ and converted to MOR (MPa). The tabulated bending stiffness values were divided by the moment of inertia $\left(\mathrm{mm}^{4}\right)$ of the sample and converted to MOE (MPa). The thickness and width of the three-layer CLT tabulated in ANSI/APA PRG 320 are $105 \mathrm{~mm}$ and $1000 \mathrm{~mm}$, respectively. Thus, the section modulus and the moment of inertia of the three-layer CLTs in ANSI/APA PRG 320 are 1,837,500 $\mathrm{mm}^{3}$ and $96,468,750 \mathrm{~mm}^{4}$, respectively. Table 5 shows the MOR and MOE for the CLTs in ANSI/APA PRG 320, which the bending moment capacity and the bending stiffness in ANSI/APA PRG 320 are divided by the section modulus $\left(1,837,500 \mathrm{~mm}^{3}\right)$ and the moment of inertia $\left(96,468,750 \mathrm{~mm}^{4}\right)$, respectively.

Table 5 Lamina requirements and bending properties for CLT grades (ANSI/APA PRG 320-2012)

\begin{tabular}{|c|c|c|c|c|}
\hline \multirow[t]{2}{*}{ CLT grades } & \multicolumn{2}{|l|}{ Requirements for lamina } & \multicolumn{2}{|c|}{$\begin{array}{l}\text { Bending properties for } \\
\text { three-layer CLT }\end{array}$} \\
\hline & Major layer & Minor layer & MOR (MPa) & $\operatorname{MOE}(\mathrm{GPa})$ \\
\hline E1 & $\begin{array}{l}\text { Grade: } 1950 \mathrm{f}-1.7 \mathrm{E} \\
\text { Species: Spruce-pine-fir } \\
\text { MOR of lamina: } 28.2 \mathrm{MPa} \\
\text { MOE of lamina: } 11.7 \mathrm{GPa}\end{array}$ & $\begin{array}{l}\text { Grade: No.3 } \\
\text { Species: Spruce-pine-fir } \\
\text { MOR of lamina: } 7.0 \mathrm{MPa} \\
\text { MOE of lamina: } 9.0 \mathrm{GPa}\end{array}$ & $22.86^{\mathrm{a}}$ & $11.28^{\mathrm{b}}$ \\
\hline E2 & $\begin{array}{l}\text { Grade: } 1650 f-1.5 \mathrm{E} \\
\text { Species: Douglas fir-larch } \\
\text { MOR of lamina: } 23.9 \mathrm{MPa} \\
\text { MOE of lamina: } 10.3 \mathrm{GPa}\end{array}$ & $\begin{array}{l}\text { Grade: No.3 } \\
\text { Species: Douglas fir-larch } \\
\text { MOR of lamina: } 4.6 \mathrm{MPa} \\
\text { MOE of lamina: } 10.0 \mathrm{GPa}\end{array}$ & $19.59^{c}$ & $9.93^{\mathrm{d}}$ \\
\hline E3 & $\begin{array}{l}\text { Grade: } 1200 f-1.2 \mathrm{E} \\
\text { Species: Eastern softwoods, } \\
\text { Northern species, or West- } \\
\text { ern woods } \\
\text { MOR of lamina: } 17.4 \mathrm{MPa} \\
\text { MOE of lamina: } 8.3 \mathrm{GPa}\end{array}$ & $\begin{array}{l}\text { Grade: No.3 } \\
\text { Species: Eastern softwoods, } \\
\text { Northern species, or West- } \\
\text { ern woods } \\
\text { MOR of lamina: } 4.5 \mathrm{MPa} \\
\text { MOE of lamina: } 6.5 \mathrm{GPa}\end{array}$ & $14.15^{\mathrm{e}}$ & $8.00^{\mathrm{f}}$ \\
\hline
\end{tabular}

${ }^{\text {a }}$ Tabulated bending moment capacity $\left(42 \times 10^{6} \mathrm{~N} \mathrm{~mm}\right)$ divided by its section modulus $\left(1,837,500 \mathrm{~mm}^{3}\right)$. ${ }^{\mathrm{b}}$ Tabulated bending stiffness $\left(1088 \times 10^{9} \mathrm{~N} \mathrm{~mm}{ }^{2}\right)$ divided by the moment of inertia of major layer $\left(96,468,750 \mathrm{~mm}^{4}\right)$. ${ }^{\mathrm{c}}$ Tabulated bending moment capacity $\left(36 \times 10^{6} \mathrm{~N} \mathrm{~mm}\right)$ divided by its section modulus $\left(1,837,500 \mathrm{~mm}^{3}\right) .{ }^{\mathrm{d}}$ Tabulated bending stiffness $\left(958 \times 10^{9} \mathrm{~N} \mathrm{~mm}^{2}\right)$ divided by the moment of inertia of major layer $\left(96,468,750 \mathrm{~mm}^{4}\right)$. ${ }^{\mathrm{e}}$ Tabulated bending moment capacity $\left(26 \times 10^{6} \mathrm{~N} \mathrm{~mm}\right)$ divided by its section modulus $\left(1,837,500 \mathrm{~mm}^{3}\right)$. ${ }^{\mathrm{f}}$ Tabulated bending stiffness $\left(772 \times 10^{9} \mathrm{~N} \mathrm{~mm}^{2}\right)$ divided by the moment of inertia of major layer $\left(96,468,750 \mathrm{~mm}^{4}\right)$ 
In this study, the MOE values of the major layer for E8 group CLT specimens (E8A and E8B) were 8.0-9.0 GPa, and the MOE values of the minor layer for the E8 groups were less than 7.0 GPa. Thus, the measured bending properties of the E8 groups were compared with E3 grade CLT materials.

The MOE of E8A (7.98 GPa) and E8B (8.04 GPa) was similar to the MOE of E3 grade CLT $(8.0 \mathrm{GPa})$. As mentioned above, this shows that the MOE of the CLT panel was strongly influenced by the MOE of the major axis layer used in fabrication. The MOR value of E8A $(\mathrm{KAR} \leq 0.5)$ was $25.09 \mathrm{MPa}, 77.3 \%$ higher than E3 grade CLT (14.15 MPa). The MOR of E8B (KAR>0.5) was $19.34 \mathrm{MPa}, 36.7 \%$ higher than E3 grade CLT. Despite the significant presence of knots $(\mathrm{KAR}>0.5)$ in the major axis layer laminae, the MOR of the experimental panels met the requirements for the E3 grade.

When lumber is used repeatedly, the effect of increasing bending strength is well known (Green and Hernandez 1998). This effect is often applied to member design by applying a repetitive member factor (AWC 2018). In CLT, when a specific graded lamina is repeatedly used in the major axis layer, there is more freedom in lamina material choice, due to this improved strength benefit.

\section{Conclusion}

To analyze the effects of the KAR on the bending properties of CLT, out-of-plane bending tests were conducted with CLT specimens with major axis layers manufactured from laminae with two different MOE grades and two different KAR limitations. The results of these tests indicate that:

1. The tension failure mode of Korean pine CLT occurred mainly from knots at the bottom of the major axis layers. The tension failure then caused a rolling shear failure in the minor axis layers.

2. The MOE grades and KAR limitation of major axis layers were the key factors affecting the bending properties of the CLT. Specifically, the effect of the major axis KAR on the MOR of the CLT was greater than the effect on the MOE.

3. The variation of the MOR values for the B group (KAR $>0.5)$ was wider than the A group $(\mathrm{KAR} \leq 0.5)$. Although the lower fifth percentile values of MOR for the B group were lower than those measured from the A group, the fifth percentile values found in the B group still satisfied the MOR criteria for the E3 grade according to ANSI/APA PRG 320. Thus, it may be sufficient to use lower-quality lumber to manufacture CLT. The efficient use of previously unused lumber can be improved by manufacturing a CLT under the condition of limitation of the greater KAR.

Open Access This article is licensed under a Creative Commons Attribution 4.0 International License, which permits use, sharing, adaptation, distribution and reproduction in any medium or format, as long as you give appropriate credit to the original author(s) and the source, provide a link to the Creative 
Commons licence, and indicate if changes were made. The images or other third party material in this article are included in the article's Creative Commons licence, unless indicated otherwise in a credit line to the material. If material is not included in the article's Creative Commons licence and your intended use is not permitted by statutory regulation or exceeds the permitted use, you will need to obtain permission directly from the copyright holder. To view a copy of this licence, visit http://creativecommons.org/ licenses/by/4.0/.

\section{References}

ANSI/APA PRG-320 (2018) Standard for performance-rated cross-laminated timber. American National Standard Institute (ANSI), New York

ASTM D198-09 (2009) Standard test methods of static tests of lumber in structural sizes. American Society for Testing and Methods, West Conshohosken

ASTM D2915-10 (2010) Standard practice for evaluating allowable properties for grades of structural lumber. American Society for Testing and Methods, West Conshohosken

ASTM D3737 (2018) Standard practice for establishing allowable properties for structural glued laminated timber (Glulam). American Society for Testing and Methods, West Conshohosken

AWC (2018) National design specification for wood construction. American Wood Council, Leesburg

Blass HJ, Görlacher R (2000) Rolling shear in structural bonded timber elements. In: Proceedings of international conference on wood and wood fiber composites, Stuttgart, Germany, pp 327-337

Chong SH, Park BS (2008) Wood properties of the useful tree species grown in Korea. Korea For Res Inst 208-228

Ehrhart T, Brandner R (2018) Rolling shear: test configurations and properties of some European softand hardwood species. Eng Struct. https://doi.org/10.1016/j.engstruct.2018.05.118

EN 16351 (2014) Timber structures — cross laminated timber-requirements. Draft version, European Committee for Standardization (CEN)

Flores ES, Saavedra K, Hinojosa J, Chandra Y, Das R (2016) Multi-scale modelling of rolling shear failure in cross-laminated timber structures by homogenisation and cohesive zone models. Int $\mathbf{J}$ Solids Struct 81:219-232

Green DW, Hernandez R (1998) Standards for structural wood products and their use in the United States. J Contem Wood Eng 9:8-9

Hematabadi H, Madhoushi M, Khazaeyan A, Ebrahimi G, Hindman D, Loferski J (2020) Bending and shear properties of cross-laminated timber panels made of poplar (Populus alba). Constr Build Mater 265:120326

Karacabeyli E, Douglas B (2013) CLT handbook. US Edition, FPInnovations and Binational Softwood Lumber Council, Point-Claire, Quebec

Korea Forest Service (2018) Statistical Annual Report for forest industry. Korea Forest Service, Daejeon

KS F 3020:2013 (2013) Softwood structural lumber. Korean Standards Association, Seoul

KS F 3021:2018 (2018) Structural glued laminated timber. Korean Standards Association, Seoul

Lam F, Barrett JD, Nakajima S (2005) Influence of knot area ratio on the bending strength of Canadian Douglas fir timber used in Japanese post and beam housing. J Wood Sci 51:18-25. https:// doi.org/10.1007/s10086-003-0619-6

National Lumber Grading Authority (NLGA) (2013) SPS 2-2013, Special products standard for machine graded lumber. National Lumber Grades Authority, Vancouver

Oh JK, Kim GC, Lee JJ (2000) Knot distribution and machine grades of Japanese larch lumber. Proc Korean Soc Wood Technol 2000:41-47

Pang SJ, Jeong GY (2019) Effects of combinations of lamina grade and thickness, and span-to-depth ratios on bending properties of cross-laminated timber (CLT) floor. Const Build Mater 222:142151. https://doi.org/10.1016/j.conbuildmat.2019.06.012

Roblot G, Bléron L, Mériaudeau F, Marchal R (2010) Automatic computation of the knot area ratio for machine strength grading of Douglas-fir and Spruce timber. Eur J Environ Civ Eng 14:13171332. https://doi.org/10.1080/19648189.2010.9693296 
Sedighi Gilani M, Heeb M, Huch A, Fink S, Schwarze FWMR (2017) Fracture in Norway spruce wood treated with Physisporinus vitreus. Wood Sci Technol 51:195-206. https://doi.org/10.1007/ s00226-016-0873-6

SOM (2013) Skidmore, Owins, Merril: timber tower research project. http://www.som.com/ideas/ research/timber_tower_research_project

Song YJ, Jung HJ, Lee IH, Hong SI (2015) Performance evaluation of bending strength of curved composite Glulams made of Korean white pine. J Korean Wood Sci Technol 34:463-469. https:// doi.org/10.5658/WOOD.2015.43.4.463

Vázquez C, Gonçalves R, Bertoldo C, Baño V, Vega A, Crespo J, Guaita M (2015) Determination of the mechanical properties of Castanea sativa Mill. using ultrasonic wave propagation and comparison with static compression and bending methods. Wood Sci Technol 49:607-622. https:// doi.org/10.1007/s00226-015-0719-7

Yeh B (1996) Using computer models to predict the performance of structural glued laminated timber. In: Proceeding of the international wood engineering conference, New Orleans, LA, USA

Publisher's Note Springer Nature remains neutral with regard to jurisdictional claims in published maps and institutional affiliations. 